\section{Sistema Único de Saúde e o terceiro setor: caracterização de entidades, não hospitalares, que possuem serviços em atenção básica de saúde em Belo Horizonte, Minas Gerais, Brasil}

\author{
The Unified National Health System and the \\ third sector: characterization of non-hospital \\ facilities providing basic health care services \\ in Belo Horizonte, Minas Gerais, Brazil
}

Claudia Marques Canabrava ${ }^{1}$ Eli Iôla Gurgel Andrade 1 Fúlvio Alves Janones 1 Thiago Andrade Alves 1 Mariangela Leal Cherchiglia 1

\footnotetext{
${ }^{1}$ Faculdade de Medicina, Universidade Federal de Minas Gerais,

Belo Horizonte, Brasil.

Correspondência C. M. Canabrava Departamento de Medicina Social e Preventiva, Faculdade de Medicina, Universidade Federal de Minas Gerais. Av. Alfredo Balena 190, 9o andar, sala 9001 , Belo Horizonte, $M G$ 30130-100, Brasil. cmbrava@yahoo.com.br
}

\begin{abstract}
In Brazil, nonprofit or charitable organizations are the oldest and most traditional and institutionalized form of relationship between the third sector and the state. Despite the historical importance of charitable hospital care, little research has been done on the participation of the nonprofit sector in basic health care in the country. This article identifies and describes non-hospital nonprofit facilities providing systematically organized basic health care in Belo Horizonte, Minas Gerais, Brazil, in 2004. The research focused on the facilities registered with the National Council on Social Work, using computer-assisted telephone and semi-structured interviews. Identification and description of these organizations showed that the charitable segment of the third sector conducts organized and systematic basic health care services but is not recognized by the Unified National Health System as a potential partner, even though it receives referrals from basic government services. The study showed spatial and temporal overlapping of government and third-sector services in the same target population.
\end{abstract}

National Health System (BR); State Reform; Voluntary Health Agencies; Basic Health Services

\section{Introdução}

Conforme determina a Constituição Federal de 1988, art. 196, ao instituir o Sistema Único de Saúde (SUS), a saúde é direito de todos e dever do Estado. Entretanto, a construção do SUS, a partir do início da década de 90, dá-se no adverso cenário de crise, reforma e ajustes estruturais impostos pelas políticas de estabilização econômica.

Este movimento de reestruturação dos governos e de sua relação com a sociedade e o mercado, denominado, em muitos países, de Reforma de Estado 1, instituiria, para alguns autores 2,3,4,5, a separação das políticas regulatórias - que permaneceriam centralizadas - das atividades de execução e prestação de serviços que passariam a ser descentralizadas.

No Brasil, a discussão da Reforma do Estado adquiriu centralidade no decorrer dos anos 90 com o imperativo de implantar novas formas de gestão pública, que permitissem a consecução das metas coletivas e viabilizassem formas alternativas de administrar a inserção na ordem globalizada 6 .

O Plano Diretor da Reforma do Aparelho do Estado (MARE) propôs a inovação dos instrumentos de política para os serviços sociais, através da implantação de organizações sociais, que, por meio de processos de publicização, produziriam bens e serviços públicos não exclusivos do Estado, incluindo-se serviços de saúde 7 . 
Neste cenário de propostas de novas formas de intervenção e organização do Estado e de sua relação com a sociedade, surge, no Brasil, a expressão "terceiro setor".

Para definir terceiro setor, encontram-se, na literatura, algumas expressões como: "organizações sem fins lucrativos", "organizações voluntárias”, "setor independente”, "caridades”, "organizações não-governamentais”, “filantropia” etc. 8,9,10,11. Além dessas variadas expressões para defini-lo, o terceiro setor apresenta uma grande diversidade interna, segundo a natureza das entidades que o compõem, incluindo-se desde entidades beneficentes de assistência social, organizações nãogovernamentais (ONGs), entidades representativas patronais e profissionais, associações de benefício mútuo até organizações de promoção e luta de interesses sociais, organizações religiosas e partidárias 12 . Contudo, Franco 12 atribui às organizações do terceiro setor cinco características que lhe são comuns: (i) estão fora da estrutura formal do Estado; (ii) não têm fins lucrativos; (iii) são constituídas por grupos de cidadãos na sociedade civil como pessoas de direito privado; (iv) são de adesão não-compulsória e (v) produzem bens e serviços de uso (interesse) coletivo.

O terceiro setor é considerado por Farah 13 como complementar às políticas universais de caráter redistributivo e de desenvolvimento, orientadas para a superação de desigualdades estruturais. Reconhecido por Tenório 14 como um importante vetor de mudança e de desenvolvimento social a partir de alianças, e, sob esse aspecto, seria um instrumento de implantação, acompanhamento e avaliação de políticas públicas junto ao Estado. Além do que, é definido, por Fischer \& Falconer 15, como um conjunto organizacional diferenciado no bojo do processo de redemocratização.

Sob outra visão, Montaño 16 tece críticas diametralmente opostas à direção dos autores até aqui citados e aponta debilidades no conceito de terceiro setor: (i) não se definiu e parece ainda não haver consenso de quais entidades o integrariam; (ii) inclui sujeitos com aparentes igualdades nas atividades, porém com interesses, espaços e significados sociais diversos, contrários e até contraditórios e (iii) parece não ser fiel o dito "não-governamental", "autogovernado" e "não-lucrativo" de entidades do terceiro setor, à medida que essas são financiadas por entidades governamentais para desempenhar as funções do Estado de forma terceirizada.

Isso posto, tanto quanto há controvérsias e ambigüidades sobre o conceito de terceiro setor há controvérsias e ambigüidades na definição de seu papel e, conseqüentemente, de sua relação com o Estado.
Para alguns autores, o terceiro setor seria a substituição do Estado nas questões sociais, por meio da terceirização disfarçada de publicização em consonância com o projeto neoliberal de minimalismo estatal 17,18 . Segundo Nogueira 19 , no Brasil, as entidades do terceiro setor tornaram-se vítimas da pobreza das políticas públicas e acabaram ou enredadas pela rigidez burocrática ou contaminadas pela excessiva proximidade com o poder. Atualmente, diversas entidades viveriam uma crise de identidade entre o não-governamental e o paraestatal.

No entanto, para outros autores, o terceiro setor seria um espaço de participação e mobilização social, importante para o desenvolvimento da democracia e para o enfrentamento das questões sociais $9,20,21$.

No Brasil, a forma de relação mais antiga, tradicional e, possivelmente, ainda a mais institucionalizada, entre Estado e "terceiro setor", é a filantropia, e, na saúde, entidades filantrópicas detêm historicamente um papel relevante na assistência hospitalar. Nos dias atuais, esse segmento se responsabiliza por cerca de 1/3 da capacidade instalada hospitalar, além de apresentar amplitude geográfica e capilaridade de rede (único estabelecimento de saúde em municípios de pequeno porte) que o credencia a cumprir papel de relevo nas políticas públicas de universalização do acesso aos serviços de saúde 22,23.

Registrando-se tanto o papel estratégico desse setor quanto a tendência, nos últimos anos, de uma política de parcerias entre Estado, sociedade e até mesmo o mercado, vários dispositivos legais foram sendo instituídos no sentido de fortalecer e reordenar os termos de cooperação entre esses atores 23. Em 1998, foi implantada a Lei das Organizações Sociais - OS - (Lei n. 9.637/98) 24; em 1999, foi decretada a Lei das Organizações da Sociedade Civil de Interesse Público - OSCIPS - (Lei n. 9.790/99) 25 e, por último, em 2004, foi sancionada a Lei de Parcerias Público Privadas - PPP (Lei n. 11.079/04) 26.

Esses dispositivos legais, ao longo da década de 90, revelam que, na conjunção da reforma do Estado e da reforma sanitária, observam-se segmentação e especialização de serviços de saúde e de clientela. Por parte do sistema público - SUS -, observa-se especialização em tecnologias de cuidados de baixo custo e complexidade, como os da atenção básica, com crescimento da atenção ambulatorial - Programa Saúde da Família (PSF) - e de hospitais públicos de pequeno porte. Enquanto isso, no sistema privado ou suplementar de saúde, percebe-se uma crescente especialização na atenção de média e alta complexidades com remuneração diferenciada de procedimentos mais complexos via tabela SUS 27,28,29,30. 
Concomitantemente, notam-se indícios de uma segmentação de clientela segundo lógicas de mercado (poder de compra), às vezes, em um mesmo espaço público, como nos hospitais universitários. Por sua vez, a proposta de parceria público/privada, por meio de organizações sociais, restringiu-se, de fato, a algumas unidades hospitalares nos Estados de São Paulo e Bahia 31.

Dessa forma, a relação público/privada, no Brasil, instituída historicamente com subsidiamento do sistema privado pelo público, consolidou-se ainda mais ambígua e contraditória na década de 90, à medida que a proposta universalizante do SUS justapõe-se a um sistema corporativo de automonia financeira e de crescente importância política, sustentado por amplo aporte de subsídios estatais diretos e indiretos 27,28,29.

Especialmente para o segmento filantrópico, o status de parceiros preferenciais do Estado, concedido às organizações sem fins lucrativos, foi confirmado, em 1988, pelo art. 199, parágrafo 1o da Constituição Federal. E, na década de 90, as instituições filantrópicas que acompanharam a modernização de gestão e o padrão de venda de serviços de alta complexidade para o setor público continuaram a receber incentivos financeiros, qualificando-se como retaguarda do sistema de saúde 22,23,27.

Porém, entidades sem fins lucrativos que prestam assistência à saúde em atenção básica ainda não são reconhecidas como uma possível estratégia de ampliação de atenção à saúde, o que é confirmado por Borges \& Fernandes 32 em seu trabalho: a participação no número de procedimentos em atenção básica, por entidades filantrópicas, em Natal, Rio Grande do Norte, Brasil, representaria apenas $0,2 \%$ do total, no ano de 1999.

A despeito de o Estado ser o responsável pela formulação e condução da política de saúde, sua parceria com as organizações sem fins lucrativos seria estratégia para viabilizar a saúde como direito de cidadania e garantir à população uma vida com qualidade 33,34.

Assim, apesar de a proposta de co-responsabilização entre Estado e sociedade civil ser bastante explicitada na agenda política nacional, da tradicional parceria entre Estado e o segmento filantrópico em saúde (segmento hospitalar) e da mobilização, em todo o país, para a reorganização da atenção básica, ainda não há, por parte dos atores institucionais, percepção de potencial de articulação entre o Estado e o "terceiro setor" na assistência básica à saúde.

Esse trabalho pretende identificar e caracterizar as entidades sem fins lucrativos que desenvolvem atividades em atenção básica de saúde, buscando contribuir para a publicização dessas ações, bem como discutir suas possíveis articulações com o SUS. Esse objetivo torna-se particularmente relevante em Belo Horizonte, uma vez que a cidade encontra-se entre as pioneiras na implantação de equipes de saúde da família, como estratégia de reorganização da atenção básica. A implantação do PSF em Belo Horizonte se deu por meio do projeto da Secretaria Municipal de Saúde denominado BH Vida: Saúde Integral, projeto esse vinculado ao programa $\mathrm{BH}$ Cidadania, coordenado pela Secretaria Municipal de Coordenação Social (SCOMPS). O BH Cidadania é um programa de inclusão social estruturado a partir dos princípios da descentralização, intersetorialidade, territorialidade e participação popular 35 .

\section{Procedimentos metodológicos}

O trabalho desenvolvido pode ser caracterizado como um estudo quanti-qualitativo de caráter exploratório e descritivo, e foi desenvolvido em duas etapas: na Etapa I, realizou-se um survey por meio de entrevista telefônica assistida por computador (ETAC) 36 às entidades sem fins lucrativos com sede em Belo Horizonte e cadastradas no Conselho Nacional de Assistência Social (CNAS) do Ministério do Desenvolvimento Social e Combate à Fome (MDS) - Brasil, no ano de 2004.

As entidades sem fins lucrativos cadastradas no CNAS têm um diferencial importante das demais do terceiro setor: são entidades de assistência social e, portanto, podem pleitear o Certificado de Entidade Beneficente de Assistência Social (CEAS).

O CEAS é imprescindível para a requisição, perante o fisco competente, do reconhecimento da imunidade ou da declaração de isenção e necessário à instrução de pedidos de benefícios e subvenções aos poderes público municipal, estadual e federal, como também para firmar convênios entre as entidades sem fins lucrativos e os poderes públicos.

Dessa maneira, as entidades sem fins lucrativos de assistência social cadastradas no CNAS, parte integrante do terceiro setor e parceiras históricas do Estado no atendimento às necessidades sociais, conformam o campo de estudo selecionado para esta pesquisa.

Os serviços organizados e sistematizados de atenção básica em saúde compreendem, nesta pesquisa, os serviços situados no primeiro nível de atenção dos sistemas de saúde e que apresentam continuidade, rotina de trabalho e sistematização 37 . Essas características são garantidas quando há, pelo menos, um profissional de 
saúde contratado ou cedido por outra entidade. Dessa forma, o vínculo estabelecido entre entidade sem fins lucrativos e o(s) profissional(is) de saúde configurou-se como a variável determinante para a qualificação das ações realizadas em saúde como "serviços organizados e sistematizados de saúde”. É importante salientar que não se pretendeu, com isso, desqualificar o trabalho de voluntários.

$\mathrm{Na}$ Etapa II, foram realizadas entrevistas semiestruturadas junto aos coordenadores das entidades, que possuem serviços organizados e sistematizados em atenção básica de saúde. E, assim, pretendeu-se caracterizar as entidades sem fins lucrativos, não hospitalares, que desenvolvem serviços organizados e sistematizados em atenção básica de saúde no Município de Belo Horizonte, no ano de 2004, identificadas na Etapa I.

Para o desenvolvimento da pesquisa, foi necessária atualização de $30 \%$ dos números telefônicos do banco de dados - CNAS/2004. Para tanto, foram consultadas as listas telefônicas não residenciais da TELEMAR/Belo Horizonte, em exercício no ano de 2004. Das 352 entidades, 52 entidades não possuíam registro nem por razão social, nem por endereço nas listas telefônicas consultadas, portanto, não foram contactadas. Outras entidades tiveram seus telefones atualizados, mas, mesmo após dez tentativas em horário comercial, as chamadas telefônicas não foram atendidas. Uma única entidade se recusou a participar da pesquisa telefônica. Dessa forma, das 352 entidades, 285 responderam à pesquisa ETAC e, portanto, obteve-se uma taxa de resposta de $81 \%$ para o universo de entidades cadastradas no CNAS e de $95 \%$ para as entidades que possuíam registro telefônico, segundo lista telefônica TELEMAR/Belo Horizonte do ano de 2004.

Na Etapa I, foram identificadas trinta entidades que possuem serviços organizados e sistematizados em atenção básica de saúde. Dessas, 28 entidades participaram da Etapa II de pesquisa (uma entidade se recusou a participar da Etapa II e apresentava dois registros no CNAS/2004).

Os cuidados éticos foram criteriosamente respeitados nas duas etapas de pesquisa (Etapa I - texto de apresentação da pesquisa enviado via fax quando solicitado; Etapa II - Termo de Consentimento Livre e Esclarecido assinado pelos entrevistados).

\section{Resultados e discussão}

A Figura 1 apresenta os resultados da pesquisa ETAC. Em Belo Horizonte, no ano de 2004, existiam 352 entidades de assistência social, sem fins lucrativos, cadastradas no CNAS/MDS - Brasil.
Desse universo, foram identificadas e caracterizadas 28 entidades sem fins lucrativos, não hospitalares, que desenvolvem serviços organizados e sistematizados em atenção básica de saúde, em Belo Horizonte, no ano de 2004. As características das 28 entidades pesquisadas serão apresentadas da seguinte maneira: Tabela 1 - características institucionais das entidades; Tabela 2 - características dos serviços de atenção básica em saúde desenvolvidos e Figura 2 - tipos de relação entre as entidades pesquisadas e o SUS/Belo Horizonte, identificadas nesta pesquisa.

Observou-se que o grupo de entidades que possuem serviços organizados e sistemáticos em atenção básica de saúde possui, proporcionalmente, mais certificados que o universo pesquisado. O que parece confirmar o perfil mais institucionalizado desse segmento.

A natureza jurídica predominante é do tipo associação (85,7\%). Uma associação, segundo Szazi ${ }^{38}$, pode ser definida como uma pessoa jurídica criada a partir da união de idéias e esforços de pessoas em torno de um propósito que não tenha finalidade lucrativa. As vantagens, previstas na Constituição, para a natureza jurídica tipo associação, são a liberdade de associação para fins lícitos, sendo vedada a interferência estatal, bastando reunião em assembléia de pessoas com maioridade civil, eleição da mesa diretora, elaboração do estatuto e inscrição no Cartório de Pessoas Jurídicas 38 .

Dessa forma, as vantagens de liberdade de constituição e gerenciamento em relação ao Estado, além da ausência de obrigação de patrimônio inicial, podem estar contribuindo para um maior número de entidades de natureza tipo associação no grupo caracterizado.

As crianças e adolescentes constituem a principal clientela $(71,4 \%$ do total de entidades caracterizadas) das entidades sem fins lucrativos de assistência social, em Belo Horizonte, no ano de 2004; e os serviços de atenção básica de saúde estão restritos à clientela já assistida em outros programas/serviços da entidade. Constatou-se, no caso da atenção aos serviços de saúde, que as entidades assumem uma responsabilidade que não é delas, acarretando discricionariedade da clientela atendida, limitada abrangência ou capacidade de cobertura e pouco impacto coletivo 39.

As 28 entidades caracterizadas demonstram preocupação em proporcionar ações que promovam capacidade de articulação social do público assistido: programas de geração de renda para chefes de família, formação profissional de adolescentes, assessoria jurídica aos portadores de HIV/AIDS, inclusão social dos portadores de necessidades especiais etc. Contudo, ainda são expressivamente assistencialistas. A condição 
Resultado da seleção das entidades.

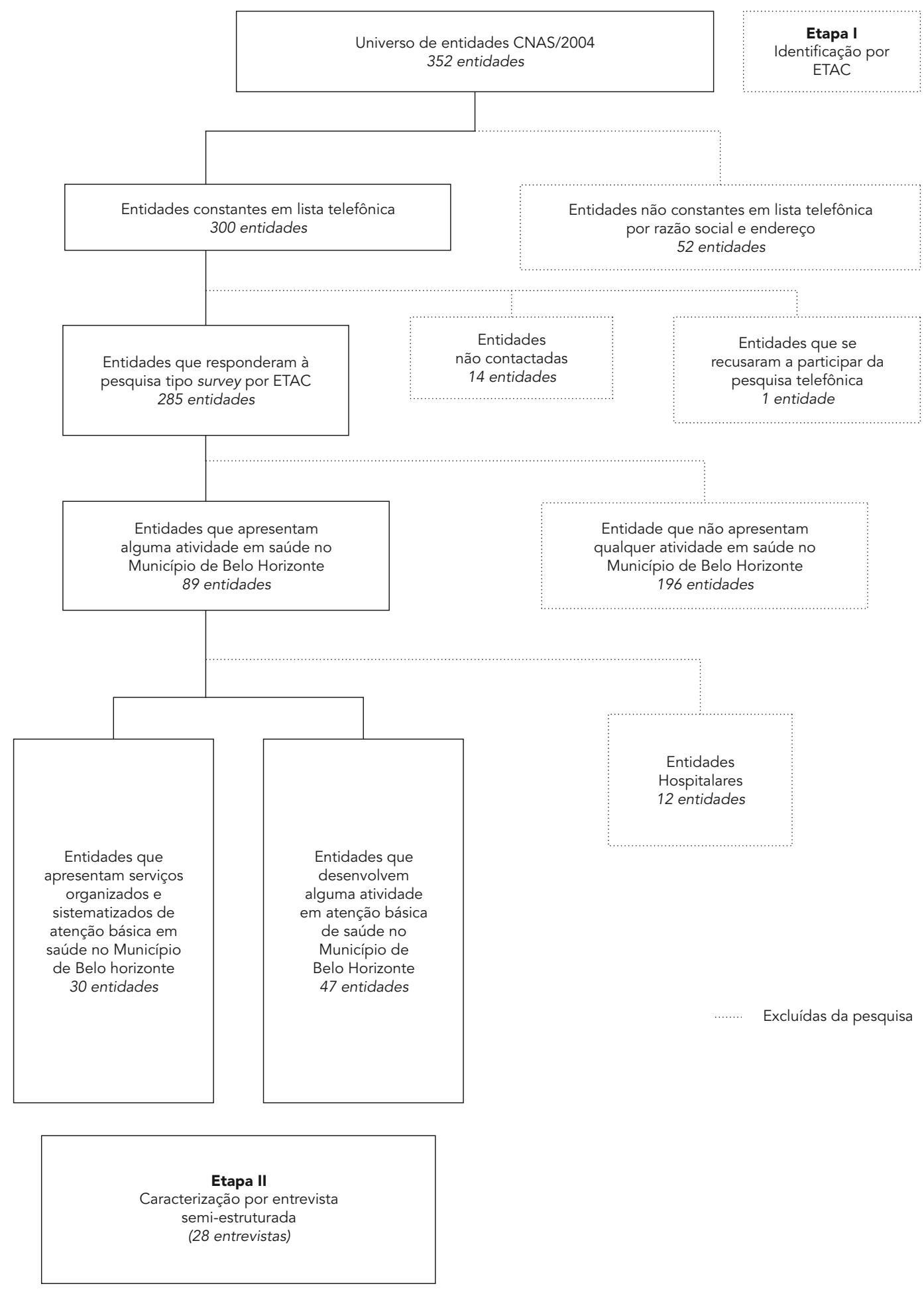

CNAS = Conselho Nacional de Assistência Social; ETAC = entrevista telefônica assistida por computador. 
Tabela 1

Características institucionais das entidades sem fins lucrativos, não hospitalares, que possuem serviços organizados e sistematizados em atenção básica de saúde. Belo Horizonte, Minas Gerais, Brasil, 2004.

\section{Variáveis}

Distribuição das entidades

segundo Classificação de

Atividades do Terceiro Setor (CLATES)

Situação no Conselho Nacional

de Assistência Social em 2004

Certificado de Entidade Beneficente

de Assistência Social (CEAS)

Natureza jurídica

Clientela assistida

Tipos de entidades

Atividades desenvolvidas

Receitas e despesas
Características

Educação (35,7\%), saúde (25\%), serviço social $(28,5 \%)$, religião $(3,6 \%)$, intermediários filantrópicos $(3,6 \%)$ e direito, defesa de direitos e política (3,6\%). Nesse grupo, encontramos proporcionalmente mais entidades classificadas como de saúde do que no universo pesquisado

$23(82,1 \%)$ filantrópicas e $5(17,9 \%)$ registradas

Das 23 entidades que possuem o CEAS: 15 (65,2\%) o receberam a partir de 1996 e

$16(69,6 \%)$ apresentavam o CEAS com data de validade vencida em dezembro de 2004

A natureza jurídica predominante é do tipo associação (86\%)

14 (50\%) prioritariamente crianças e adolescentes, 6 (21,4\%) portadores de necessidades especiais, $5(17,9 \%)$ adultos e $3(10,7 \%)$ idosos

Creches (11 entidades), entidades que assistem os portadores de necessidades especiais (7 entidades), asilos (3 entidades) e outras (7 entidades)

10 (35,7\%) educação (infantil e para adolescentes); 6 (21,4\%) assistência social (assistência a portadores de HIV/AIDS, crianças e jovens, assistência a famílias); 5 (17,9\%) desenvolvem serviços de educação, assistência social e saúde para portadores de necessidades especiais; 4 (14,3\%) moradia (3 para idosos e 1 para portadores de necessidades especiais); 3 (10,7\%) entidades que trabalham prioritariamente com atendimento à saúde (HIV/AIDS, adolescentes e dependentes químicos de drogas) assistencialista mencionada remete ao entendimento de que o assistencialismo é "um estilo, um modo de fazer, que tem como conseqüencia criar uma relação de submissão e não oferecer os instrumentos para superação das carências que estão sendo minoradas" 40 (p. 43). Dessa forma, como apontou Cardoso 40 (p. 43), “ainda hoje com freqüência nos deparamos com programas sociais, governamentais ou filantrópicos que apresentam uma retórica antiassistencialista, mas cuja prática repete os velhos métodos".

É interessante observar que 25 entidades $(89,3 \%)$ declaram usufruir de imunidade em algum tipo de encargo tributário municipal (como, por exemplo, o Imposto Predial e Territorial Urbano - IPTU), e vinte entidades usufruem de isenção patrimonial da cota patronal do Instituto Nacional de Seguro Social - INSS -, porém, os recursos que deixam de ser captados pelo Estado não são necessariamente contabilizados pelas entidades quando essas declaram sua receita/ despesa. Além do que, 23 entidades possuem algum tipo de convênio com a Prefeitura Municipal de Belo Horizonte, principalmente desenvolvido com a Secretaria Municipal de Abastecimento (SMAB) ou com a Secretaria Municipal de Educação (SME).

Dessa forma, a atuação do poder público na manutenção dessas entidades é substancialmente mais expressiva do que declarada durante as entrevistas: a maioria se expressa em relação aos convênios como importantes, mas irrisórios, muito mais próximos do sentido de ajuda do que de participação governamental na manutenção da entidade. E as isenções, imunidades e subvenções tributárias são entendidas como próprias e naturais, já que as entidades estão "ajudando o Estado" nas questões sociais. 
Características dos serviços organizados e sistematizados em atenção básica de saúde desenvolvidos por entidades sem fins lucrativos, não hospitalares. Belo Horizonte, Minas Gerais, Brasil, 2004.

Serviços organizados e sistematizados em atenção básica de saúde

Clientela assistida

Áreas de saúde desenvolvidas

Tempo em que os serviços de atenção básica em saúde estão sendo desenvolvidos

Motivo do desenvolvimento dos serviços em atenção básica de saúde

Organização e infra-estrutura
Os serviços de atenção básica de saúde estão restritos à clientela já assistida em outros programas/serviços da entidade

Odontologia: 15 (53,6\%); Medicina: 14 (50\%); Psicologia: 13 (46,4\%); Fisioterapia: 9 (32,1\%); Nutrição: 9 (32,1\%); Enfermagem: 8 (28,6\%); Terapia Ocupacional: 7 (25\%); Fonoaudiologia: 6 (21,4\%); Farmácia: 3 (10,7\%)

Na maioria das entidades caracterizadas, os serviços de saúde começaram a ser oferecidos a partir da década de 1990; das entidades que desenvolvem serviços de saúde há mais de 15 anos, destacam-se as entidades que assistem os portadores de necessidades especiais

"Necessidade sentida e reivindicada pela comunidade" ou necessária à assistência (como, por exemplo, portadores de necessidades especiais e AIDS)

A maioria das entidades declara não haver fila de espera para os atendimentos em saúde, geralmente organizados por consultas programadas. As entidades possuem equipamentos e infra-estrutura adequados para o atendimento realizado em atenção básica de saúde, sendo as entidades que assistem os portadores de necessidades especiais as que apresentam maior complexidade em equipamentos e infra-estrutura para o atendimento em saúde

Das 28 entidades, 26 apresentam profissionais de saúde de nível superior contratados para o atendimento em cada especialidade desenvolvida, e apenas 2 entidades trabalham apenas com profissionais cedidos. Além dos profissionais contratados, 5 entidades possuem voluntários, e 8 possuem estagiários para os atendimentos de saúde (alunos de graduação e pós-graduação de universidades de Belo Horizonte)
No entanto, em estudo desenvolvido pela Johns Hopkins University, no caso do Brasil, cerca de $15 \%$ dos recursos financeiros utilizados pelas organizações do terceiro setor (estimado em US\$ 10,9 bilhões, em 1995) tiveram origem nos orçamentos públicos 19 .

As entidades caracterizadas parecem estar muito mais próximas da condição de entidades paraestatais. A afirmação de que a condição paraestatal das entidades resulta numa relação mutualística entre governo e terceiro setor ${ }^{19}$ parece ser confirmada no grupo caracterizado, ao observar a relação entre o financiamento governamental não declarado e a ausência de controle do Estado nas ações desenvolvidas.

Já em relação à participação internacional no financiamento do terceiro setor, Mansur $41 \mathrm{ex}$ plicita sua preocupação: $83 \%$ das ONGs brasileiras recebem recursos internacionais, e é, desta forma, inquietante "a orientação e as prioridades que chegam junto com o dinheiro" 41 (p. 52). Chama atenção que, no grupo das entidades caracte- rizadas neste trabalho, 28,5\% recebem recursos externos e atuam sob condições predeterminadas pelo financiador internacional.

\section{Relação com o SUS de Belo Horizonte}

No grupo de entidades pesquisadas, podemos verificar três possibilidades de relação com o SUS de Belo Horizonte: (i) parceria - estabelecimento de alguma relação de "parceria" com o sistema municipal de saúde, ainda que informalmente; (ii) paralelismo - superposição e concomitância de ações e recursos do segmento filantrópico e do SUS de Belo Horizonte em uma mesma população e (iii) paraestatal - manutenção de relação unilateral, na qual o SUS de Belo Horizonte utiliza-se das entidades sem fins lucrativos para o desenvolvimento de suas ações e/ou encaminhamento de pacientes. Desse grupo, apenas 1 entidade $(3,6 \%)$ não estabelece nenhum desses três tipos de relação como o SUS de Belo Horizonte (desenvolve assistência psicológica es- 
Formas de relação entre o terceiro setor e o Sistema Único de Saúde em Belo Horizonte (SUS/BH),

Minas Gerais, Brasil, 2004.
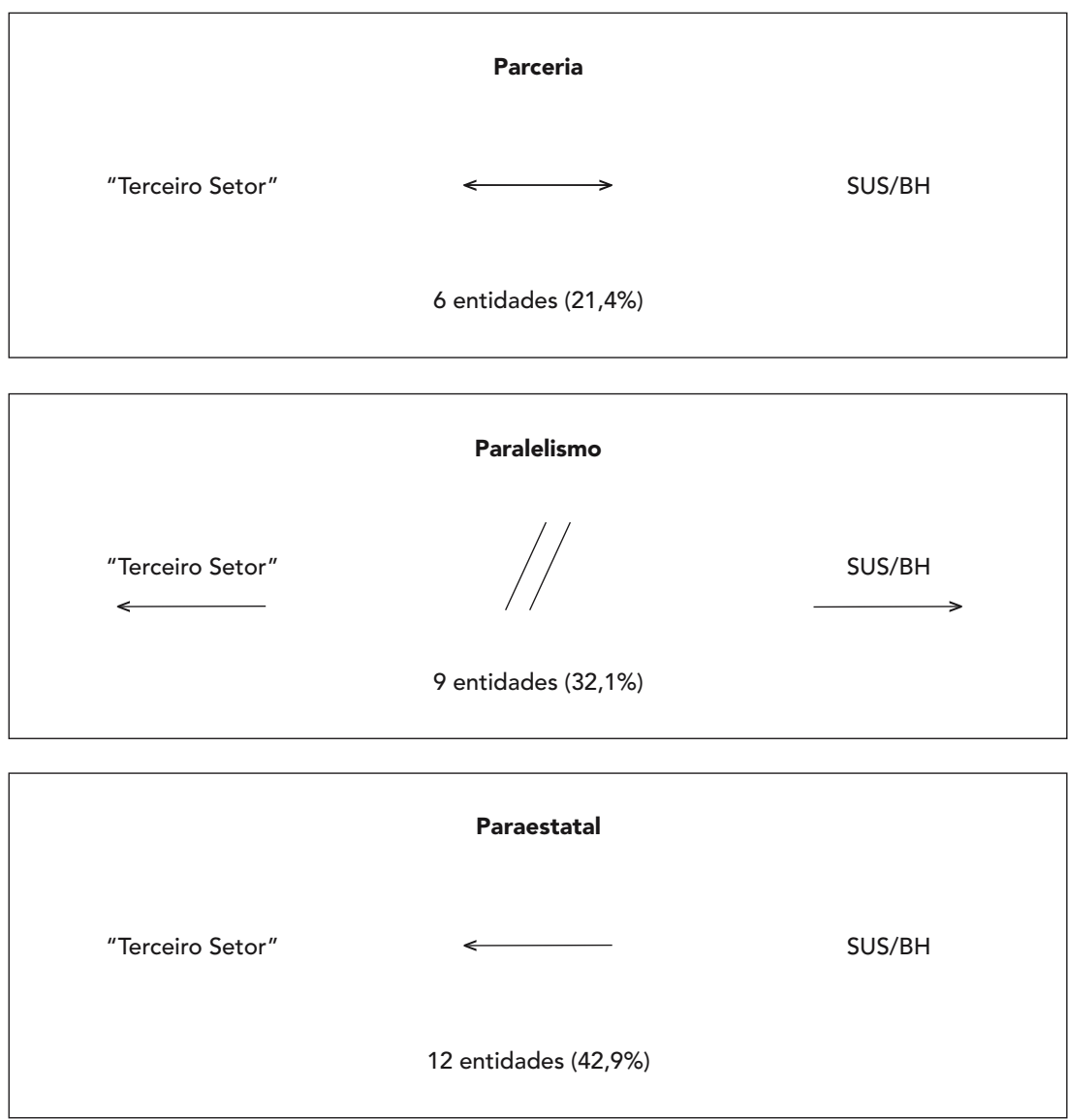

pecialmente para portadores de HIV/AIDS). A Figura 2 representa as relações entre entidades pesquisadas e o SUS de Belo Horizonte.

Verificou-se que seis entidades mantêm alguma relação de "parceria" com o SUS de Belo Horizonte. No entanto, essa ocorre de forma tênue, informal e é determinada, em nível local, por meio de acordos estabelecidos entre gerentes de centros de saúde e coordenadores das entidades. São exemplos de relação de "parceria" encontrada: presença de equipes de saúde da família atendendo à clientela da entidade e à população em geral, enquanto a entidade cede suas instalações físicas e recursos humanos para a organização do atendimento; parceria para treinamento de agentes comunitários; presença de recursos humanos cedidos pela Prefeitura Municipal de
Belo Horizonte para atendimento em saúde nas instalações das entidades.

Constatou-se, também, que nove entidades desenvolvem ações em saúde muito semelhantes em recursos e metodologia às ações desenvolvidas pelo SUS de Belo Horizonte: creches que desenvolvem ações no combate à desnutrição infantil, com cuidado à gestante e à criança, em seu âmbito familiar e social, utilizando-se de "animadores comunitários" (moradores da comunidade onde atuam) para identificação e controle das enfermidades, além de prestarem cuidados diretos em enfermagem e medicina. Nessa mesma comunidade, encontram-se equipes de saúde da família atuando no combate à desnutrição, no cuidado à gestante e à criança. Os "animadores comunitários” das entidades caracterizadas são 
selecionados e treinados muito semelhantemente aos agentes comunitários de saúde presentes nas equipes de saúde da família. Infelizmente, esse tipo de relação ora resulta em disputa por clientela, ora em duplicidade e sobreposição de ações e recursos sobre uma mesma população.

Já a relação “unilateral” de utilização dos serviços estabelecida entre o SUS de Belo Horizonte e as entidades sem fins lucrativos se dá quando o SUS de Belo Horizonte, dentre outros órgãos públicos (Promotoria da Infância e da Adolescência, por exemplo), referencia pessoas para os atendimentos de saúde e outros serviços prestados pelas entidades sem, contudo, haver relação de parceria em saúde, permanecendo os serviços de saúde prestados pelas entidades à margem do sistema de atenção básica em saúde. São exemplos da relação unilateral encontrada: referenciamento para atendimento em saúde aos portadores de necessidades especiais, aos dependentes químicos, às casas de apoio a pacientes com câncer e HIV/AIDS e alguns atendimentos específicos como: fisioterapia, hebiatria e psicologia.

Isso posto, talvez ainda não haja, de fato, coresponsabilização entre Estado e "terceiro setor" (filantrópico) no seguimento saúde (atenção básica de saúde) das políticas sociais: o Estado as qualifica como entidades de assistência social, garante-lhes alguns benefícios, define como um de seus objetivos a prestação de serviços de saúde e permite considerável liberdade de ação prevista na própria Lei Orgânica da Assistência Social-LOAS (Lein. 8.742/93) ${ }^{42}$, enquanto as entidades usufruem desses benefícios, atendem à clientela beneficiária da LOAS, mas definem suas ações e metas ou a partir de agentes financiadores estrangeiros ou por critérios de gerenciamento próprio. A criação das OS e das OSCIPS pretendia mudar essa relação através de contratos de gestão e termos de parceria para essas entidades, porém a regulação pelo Estado permanece ainda enquanto ações isoladas de pouca visibilidade social. Nesse caso, as relações de cooperação ainda não migraram das alianças tradicionais para alianças estratégicas, como postulava Austin 43 ao afirmar que, com certeza, o século XXI seria a "era das alianças".

Podemos ainda considerar que a proposta de inovação dos instrumentos de política para os serviços sociais, através dos mecanismos de publicização, contidos na Reforma do Estado, aproxima-se, para o caso aqui estudado, muito mais da criticada transferência de responsabilidades do Estado, do que da desejada assimilação das potencialidades do terceiro setor na resolução de questões sociais junto ao Estado 16,17,18.

Além do que, novas formas de parcerias implicam proeminentemente na modalidade de gerência sob a forma de contratos, na introdução de mecanismos de mercado no setor público estatal e no estabelecimento de vinculação de pagamento e medidas de desempenho, em detrimento de questões mais amplas de inclusão e exclusão social 28 .

Reforça-se a constatação de que, quanto mais forte é a presença social do Estado, maiores as possibilidades de sinergia e atuação conjunta com o terceiro setor, o qual não assume a responsabilidade pela prestação de serviço público, mas, sim, o seu papel propositivo e inovador no planejamento e implementação das políticas, bem como o fiscalizatório e avaliador de tais políticas 39 .

\section{Considerações finais}

As entidades do terceiro setor caracterizadas como entidades que possuem serviços organizados e sistematizados de atenção básica em saúde, apesar de demonstrarem preocupação com ideários de cidadania e desenvolvimento sustentável (programas de geração de renda para chefes de família, formação profissional de adolescentes, assessoria jurídica aos portadores de HIV/AIDS, inclusão social dos portadores de necessidades especiais etc.), ainda são expressivamente assistencialistas.

O grupo caracterizado presta serviços de atenção básica em saúde, em acordo com a conceituação clássica prevista pelo SUS, porém, não estabelece (na maioria) qualquer relação de parceria com o SUS municipal, embora, paradoxalmente, sejam referência para encaminhamentos originados de diversos órgãos públicos.

Dessa forma, na profusão de ações assistenciais desenvolvidas, as ações de saúde permanecem meramente pontuais e isoladas, não se conformando enquanto parte de uma política pública, e, nesse caso, as entidades pesquisadas parecem estar muito mais próximas da condição de paraestatais enquanto "muletas do Estado" em suas diversas disfuncionalidades. Ademais, esse estudo permitiu constatar a existência de paralelismo e até mesmo sobreposição de ações e recursos para uma mesma clientela e território, exatamente quando se busca construir uma política municipal voltada para a transformação do cuidado individual em cuidado coletivo com ênfase na organização territorial. O paralelismo de ações e recursos, muitas vezes, tornam as entidades "concorrentes" do Estado, levando a uma relação conflituosa de disputa na assistência.

Por outro lado, é inegável que essas entidades executavam ações importantes e de qualida- 
de em assistência social e em atenção básica de saúde para uma determinada clientela, no $\mathrm{Mu}$ nicípio de Belo Horizonte, no ano de 2004, e não podem, por isso, serem destituídas de seu valor. Trata-se, assim, de reconhecer que as entidades caracterizadas executam ações que têm grande aderência com a clientela assistida, mas que ainda não são "percebidas" pelo Estado.

Apesar de o "discurso do Estado", reeditado desde a proposta de Reforma, com a implantação da Lei das Organizações Sociais, da Lei das Organizações da Sociedade Civil de Interesse Público e até mesmo da Lei de Parcerias Público Privadas, ser de co-responsabilização entre Estado e terceiro setor, prevalecem, na relação público/privada em saúde, a interdependência no financiamento e na prestação de serviços.

Dessa forma, este estudo remete-nos a alguns desafios: como fazer com que as entidades

Resumo

No Brasil, as entidades sem fins lucrativos ou filantrópicas representam a forma mais antiga, tradicional e institucionalizada de relação do terceiro setor com o Estado. Contudo, apesar da importância histórica da filantropia na assistência hospitalar, ainda é pouco estudada a participação do segmento filantrópico em atenção básica de saúde no Brasil. Este artigo apresenta o trabalho de identificação e caracterização de entidades sem fins lucrativos, não hospitalares, que possuem serviços organizados e sistematizados em atenção básica de saúde, em Belo Horizonte, Minas Gerais, Brasil, 2004. A pesquisa foi realizada a partir do universo de entidades cadastradas no Conselho $\mathrm{Na}$ cional de Assistência Social, utilizando-se entrevistas telefônicas assistidas por computador e entrevistas semi-estruturadas. A identificação e descrição dessas entidades mostraram que o segmento filantrópico do terceiro setor desenvolve serviços organizados e sistemáticos em atenção básica de saúde, entretanto, não é reconhecido como potencial parceiro pelo SUS, embora seja referência para encaminhamentos de diversos órgãos públicos. Observa-se sobreposição e concomitância de ações e recursos públicos e do terceiro setor em uma mesma população.

Sistema Único de Saúde; Reforma do Estado; Instituições Filantrópicas de Saúde; Serviços Básicos de Saúde possam se tornar partícipes do processo universalizante em saúde; como evitar ou minimizar a duplicidade de recursos e serviços para uma mesma clientela; como enfrentar o desafio de fazer com que o terceiro setor possa ser parceiro e não somente complementar ao Estado?

Para tanto, é essencial potencializar novas formas de relação entre Estado e sociedade, que promovam a autonomia dos sujeitos sociais em contraposição à lógica de mercado, que reforça a condição de cidadãos consumidores de serviços providos pelo Estado e pelo terceiro setor.

Isto posto, os caminhos observados nesse estudo apontam que a potencialidade de parceria e sinergia entre o Estado e o terceiro setor passa pelo reconhecimento de que as ações desse serão tanto mais efetivas, quanto mais pautadas por critérios ditados por políticas públicas socialmente reconhecidas.

\section{Colaboradores}

C. M. Canabrava e M. L. Cherchiglia realizaram o desenho do estudo. C. M. Canabrava realizou a coleta de dados das etapas de pesquisa e contou com a colaboração de F. A. Janones e T. H. Alves para coleta de dados da Etapa I. C. M. Canabrava, M. L. Cherchiglia e E. I. G. Andrade realizaram análise dos dados coletados e revisão final deste texto.

\section{Agradecimentos}

Este trabalho contou com o apoio institucional e financeiro da Fundação de Amparo à Pesquisa do Estado de Minas Gerais, Conselho Nacional de Desenvolvimento Científico e Tecnológico e com o apoio em equipamentos e instalações do Núcleo de Estudo em Saúde Coletiva/Estação de Pesquisa e Sinais de Mercado para realização da Etapa I da pesquisa. 


\section{Referências}

1. Meireles EC, El-Aouar WA. O desafio das ONGs ante a minimização do papel do Estado no cenário global. Caderno de Pesquisas em Administração 2002; 9:1-12.

2. Bresser-Pereira LC. Reforma do Estado para a cidadania: a reforma gerencial brasileira na perspectiva internacional. São Paulo: Editora 34; 1998.

3. Bresser-Pereira LC. A reforma gerencial do Estado de 1995. Revista de Administração Pública 2000; 34:7-26.

4. Almeida C. Eqüidade e reforma setorial na América Latina: um debate necessário. Cad Saúde Pública 2002; 18:23-6.

5. Cherchiglia ML. O conceito de eficiência na reforma setorial do Estado brasileiro nos anos 90: difusão e apreensão em um hospital público [Tese de Doutorado]. São Paulo: Faculdade de Saúde Pública, Universidade de São Paulo; 2002.

6. Diniz E. Globalização, reforma do Estado e teoria democrática contemporânea. São Paulo Perspect 2001; 15:13-22.

7. Ministério da Administração Federal e Reforma do Estado. Organizações sociais. Brasília: Ministério da Administração Federal e Reforma do Estado; 1997. (Cadernos MARE da Reforma do Estado, 2).

8. Coelho SCT. Terceiro setor: um estudo comparativo entre Brasil e Estados Unidos. São Paulo: Editora Senac; 2000.

9. Fernandes RC. O que é o terceiro setor. In: Ioschpe EB, organizador. Terceiro setor: desenvolvimento social sustentado. Rio de Janeiro: Paz e Terra; 1997. p. 25-33.

10. Landim L. Para além do mercado e do Estado? Filantropia e cidadania no Brasil. Rio de Janeiro: Instituto de Estudos da Religião; 1993.

11. Bresser-Pereira LC, Grau NC. Entre o Estado e o mercado: o público não-estatal. In: Bresser-Pereira LC, Grau NC, organizadores. O público não-estatal na Reforma do Estado. Rio de Janeiro: Editora FGV; 1999. p. 15-48.

12. Franco A. A reforma do Estado e o terceiro setor: cinco perguntas preliminares, uma pergunta fundamental e uma nota. In: Seminário Internacional Sociedade e a Reforma do Estado. http://www. planejamento.gov.br/arquivos_down/seges/publicacoes/reforma/seminario/AugustoFranc_.pdf (acessado em 07/Abr/2004).

13. Farah MFS. Parcerias, novos arranjos institucionais e políticas públicas no nível local de governo. Revista de Administração Pública 2001; 35:119-44.

14. Tenório FG. Aliança e parceria: uma estratégia em Alves \& Cia. Revista de Administração Pública 2000; 34:35-52.

15. Fischer RM, Falconer AP. Desafios da parceria governo e terceiro setor. Revista de Administração da Universidade de São Paulo 1998; 33:12-9.

16. Montaño C. Terceiro setor e questão social: crítica ao padrão emergente de intervenção social. São Paulo: Cortez Editora; 2003.

17. Montaño C. Das lógicas do Estado às lógicas da sociedade civil: Estado e "terceiro setor" em questão. Serviço Social \& Sociedade 1999; (59):47-79.
18. Sobottka EA. A utopia-emancipatória em transição: movimentos sociais viram ONGs que viram "terceiro setor". Teoria \& Sociedade 2003; 11:48-65.

19. Nogueira R. Que bicho é esse? Primeira Leitura 2004; (30):28-31.

20. Cardoso R. Fortalecimento da sociedade civil. In: Ioschpe EB, organizador. Terceiro setor: desenvolvimento social sustentado. Rio de Janeiro: Paz e Terra; 1997. p. 7-12.

21. Landim L, Beres N, organizadores. Ocupações, despesas e recursos: as organizações sem fins lucrativos no Brasil. Rio de Janeiro: Editora Nau; 1999.

22. Gerschman SV, Barbosa PR, Lima SML, Ugá AD, Portela MC, Vasconcelos MM. O setor hospitalar filantrópico e alguns desafios para as políticas públicas em saúde. Revista de Administração Pública 2003; 37:265-83.

23. Girardi SN, Cherchiglia ML, Araújo JF. Formas institucionais de terceirização de serviços de saúde na rede hospitalar filantrópica. In: Falcão A, organizador. Observatório de recursos humanos em saúde no Brasil: estudos e análises. Rio de Janeiro: Editora Fiocruz; 2002. p. 191-225

24. Brasil. Lei n. 9.637, de 15 de maio de 1998. Dispõe sobre a qualificação de entidades como organizações sociais, a criação do Programa Nacional de Publicização, a extinção dos órgãos e entidades que menciona e a absorção de suas atividades por organizações sociais, e dá outras providências. Diário Oficial da União; 18 mai.

25. Ferrarezi E. OSCIP - Organização da sociedade civil de interesse público: a Lei 9.970/99 como alternativa para o terceiro setor. Brasília: Comunidade Solidária; 2000.

26. Brasil. Lei n. 11.079, de 30 de dezembro de 2004. Institui normas gerais para licitação e contratação de parceria público-privada no âmbito da administração pública. Diário Oficial da União; $31 \mathrm{dez}$.

27. Santos MABS, Gerschman S. As segmentações da oferta de serviços de saúde no Brasil - arranjos institucionais, credores, pagadores e provedores. Ciênc Saúde Coletiva 2004; 9:795-806.

28. Cohn A, Elias PEM. Eqüidade e reformas na saúde nos anos 90. Cad Saúde Pública 2002; 18 Suppl: 173-80.

29. Noronha JC, Soares LT. A política de saúde no Brasil nos anos 90. Ciênc Saúde Coletiva 2001; 6:445-50.

30. Gerschman S. Las reformas del Estado, de las políticas socials y de salud. Un balance del final de milenio. Cad Saúde Pública 1999; 15:293-302.

31. Ibañez N, Bittar OJNV, Sá ENC, Yamamoto EK, Almeida MF, Castro CGJ. Organizações sociais de saúde: o modelo do Estado de São Paulo. Ciênc Saúde Coletiva 2001; 6:391-404.

32. Borges DF, Fernandes KC. A descentralização das ações e serviços de saúde do SUS na cidade de Natal: democratização ou privatização? Revista de Administração Pública 2002; 36:565-85.

33. Oliveira WF, Junqueira LAP. Questões estratégicas na reforma sanitária: o desenvolvimento do terceiro setor. Revista de Administração Pública 2003; 37:227-41. 
34. Junqueira LAP, Malik AM. Saúde: público X privado [Apresentação] Revista de Administração Pública 2003; 37:183-7.

35. Secretaria de Coordenação das Políticas Sociais/ Secretaria Municipal de Saúde. BH-Vida: saúde integral: diretrizes para o avanço e articulação do processo assistencial na SMSA para o período de 2003-2004. http://www.pbh.gov.br/smsa/biblioteca/gabinete/bhvidasaudeintegral.doc (acessado em 07/Jul/2003).

36. Babbie E. Métodos de pesquisa de survey. Belo Horizonte: Editora UFMG; 1999.

37. Starfield B, organizador. Atenção primária: equilíbrio entre necessidades de saúde, serviços e tecnologia. Brasília: Ministério da Saúde/Organização das Nações Unidas para a Educação, a Ciência e a Cultura; 2002.
38. Szazi E. Terceiro setor: regulação no Brasil. 2a Ed. São Paulo: Editora Peirópolis; 2001.

39. Tavares LS. O público e o privado na análise da questão social brasileira. In: Heimann LS, Ibanhes LI, Barbosa R, organizadores. O público e o privado na saúde. São Paulo: Editora Hucitec; 2005. p. 57-87.

40. Cardoso R. Sustentabilidade, o desafio das políticas sociais no século 21. São Paulo Perspect 2004; 18:42-8.

41. Mansur A. O que elas querem? Revista Veja 2000; 14 jun.

42. Brasil. Lei Orgânica da Assistência Social, Lei n. 8.742, de 7 de dezembro de 1993. http://www. planalto.gov.br/ccivil 03/Leis/L8742.htm (acessado em 01/Jun/2004).

43. Austin J. Parcerias: fundamentos e benefícios para o terceiro setor. São Paulo: Futura; 2001.

Recebido em 03/Nov/2005

Versão final reapresentada em 13/Mar/2006

Aprovado em 20/Abr/2006 